\title{
Minimum Acceptable Diet and its Predictors among Children Aged 6-23 Months in Mareka District, Southern Ethiopia: Community Based Cross-Sectional Study
}

\author{
Fentaw Wassie Feleke and Getahun Fentaw Mulaw*
}

\author{
Department of Public Health, College of Health Sciences, Woldia University, Woldia, Ethiopia
}

\begin{abstract}
Background: Optimal infant and young child feeding practices are essential for normal growth, better health, and mental and physical development. Even though there are a lot of nutrition intervention programs in Ethiopia, still suboptimal feeding practices are prevalent. This study was devised to assess a level of minimum acceptable diet (MAD) and predictors among children aged 6-23 months in Mareka District, south Ethiopia.

Method: A community-based cross-sectional study was employed on 662 study participants from August 15 to September 15/2015. They were selected by a multi-stage sampling technique. Data were collected by intervieweradministered semi-structured questionnaires. Statistical significance was declared at $p$-value $<0.05$ at multivariable logistic regression.

Result: The study showed that $35.5 \%$ of the children aged $6-23$ months met the recommended MAD. Maternal primary and secondary education (AOR: $1.90 ; 95 \% \mathrm{Cl}: 1.15-3.16$ and AOR: $2.06,95 \% \mathrm{Cl}: 1.12-3.77$ ), Media exposure (AOR: 2.16; $95 \% \mathrm{Cl}: 1.46-3.29$ ), health facility delivery (AOR:2.52; $95 \% \mathrm{Cl}: 1.54-4.13$ ), child age of $9-11$ and $12-23$ months (AOR:2.73; 95\% Cl: 1.41-5.49 and AOR:2.55; 95\% Cl: 1.39-4.69) and GMP service utilization (AOR: 4.09; $95 \%$ Cl: 2.516.65) were associated with MAD of children.

Conclusion: The level of MAD among children was low. Maternal educational status, media exposure, institutional delivery, child age, and GMP service utilization were associated with MAD. Increasing utilization of GMP service, health facility delivery, maternal education, and media promotion was recommended to increase the level of MAD.
\end{abstract}

Keywords: Minimum Acceptable diet, children, 6-23 months, dietary diversity, Ethiopia.

\section{BACKGROUND}

Malnutrition persists at unacceptably high levels on a global scale. Globally, among children aged under five years, 149.0 million are stunted, and 49.5 million are wasted [1]. Despite some improvements in selected nutrition indicators, progress is insufficient to meet the 2025 global nutrition targets. An undernourished child has a nine times higher risk of mortality as compared with an optimally nourished child [2]. Almost half (45\%) of all child death resulted in the effect of malnutrition, and the highest figure was in Africa [3].

The immediate causes of infant and child malnutrition are inadequate dietary intake and disease, while the underlining causes are inadequate access to food and insufficient health services for the child, and an unhealthy environment [4]. Optimal infant and young child feeding practices are important for normal growth, better health, and mental and physical development, especially for children aged 6-23 months [5, 6]. Nearly one-third of child deaths could be prevented by optimal complementary feeding practices $[7,8]$. Implementing optimal complementary feeding, consumption of

*Address correspondence to this author at the Department of Public Health, College of Health Sciences, Woldia University, Woldia, P.O.BOX:400, Ethiopia; Tel: +251910143645; E-mail: gechfentaw1014@gmail.com diversified diet, and optimal meal frequency are core indicators for monitoring feeding practices of infants and young children [4]. The MAD is a composite indicator defined as the proportion of children aged 623 months who met both minimum dietary diversity (MDD) and the minimum meal frequency (MMF) during the previous 24 hours [7].

Nowadays, the Ethiopian government also set targets to improve the nutritional status of children and to end child malnutrition by 2030 through implementing different programs and strategies such as the National Nutrition Program (NNP) [9], Health Sector Transformation Plan (HSTP) [10, 11], Health Extension Program (HEP) [12], Sustainable Undernutrition Reduction in Ethiopia (SURE) [13] and seqota declaration [14]. Despite the above efforts, currently, $37 \%, 21 \%$, and $7 \%$ under five years children were stunted, underweight, and wasted, respectively [15]. In Ethiopia, only $7 \%$ of children aged $6-23$ months have met the MAD [16].

Even though some studies were conducted on the determinants of complementary feeding in Ethiopia, inadequate information was documented about MAD separately. Notably, there were no studies that investigated MAD in South Ethiopia. The finding of this study will assist the national nutrition program (NNP) to 
monitor the changes and design interventions for reducing under-nutrition in the country. Therefore, this study was devised to assess the level of MAD and associated factors among children aged 6-23 months in Mareka District, South Ethiopia.

\section{METHODS}

\section{Study Setting and Period}

The study was conducted in Mareka District, Dawro zone, south Ethiopia from August 15 to September 15, 2015. Mareka District was one of the 11 districts in the Dawro zone. It is $455 \mathrm{~km}$ far from Addis Ababa, which is the capital city of Ethiopia, and $311 \mathrm{~km}$ from Hawassa, which the capital city of the SNNPR regional state was.

According to the projection of the Ethiopian 2007 census, the district had a total population of 63,022 , of which 32,141 were males and 30,881 females. There were 3,239 under two years old children, of which 2,212 were lie in the age range of 6-23 months (Mareka District health department report). There was one health center and 15 functional health posts in the district. The communities largely depended on agriculture for their livelihood. The staple food in the highland was locally known as enset (kocho), whereas corn and sorghum were common in low-land areas. Common cash crops were wheat and teff.

\section{Study Design}

A community-based cross-sectional study design was conducted.

\section{Source Population}

All children aged 6-23 months living in Mareka District were the source population. Respondents drawn from the randomly selected kebeles were considered as the study population.

\section{Exclusion and Inclusion Criteria}

Children were excluded if they were residents for more than six months in the district.

\section{Sample Size Determination}

The minimum sample size was calculated using the single population proportion formula with EPI-info version 7.1 considering $95 \% \mathrm{Cl}, 5 \%$ margin of error, different proportions from different studies done in Africa, $10 \%$ non-response allowance, and a design effect of 2. Finally, the required size was 710 , since this was found the largest from all calculated sample sizes (Table 1).

Table 1: Sample Size Calculation using Different Proportions from Different Studies to Determine the Level of MAD among Children 623 Months in Mareka District, Southern Ethiopia, 2016

\begin{tabular}{|c|c|c|}
\hline Proportion of MAD (P) & Reference & Total sample size \\
\hline \hline 7 & {$[16]$} & 220 \\
\hline 29.9 & {$[17]$} & 710 \\
\hline 28.2 & {$[18]$} & 686 \\
\hline 15.9 & {$[19]$} & 452 \\
\hline
\end{tabular}

\section{Sampling Technique and Procedure}

A multi-stage sampling technique was employed. The selected district had a total of 15 kebeles, which were stratified into two urban and thirteen rural kebeles. The four kebele from rural and one from urban were selected randomly. The sample size was then allocated based on population proportional to the size of under-five children of each kebele. Then study units were selected using a systematic random sampling method (Figure 1).

\section{Data Collection Techniques and Quality Control}

Data were collected using a semi-structured questionnaire via face to face interviews with mothers of children aged 6-23 months. The questionnaire was prepared in English and translated into the local language (Dawurgna and Amharic). The study tool was pretested on $10 \%$ of the sample size in non-selected kebeles. Six diploma holder health professional data collectors and three masters' holder supervisors, who were fluent in the local language, were recruited. Two days of training was given for data collectors and supervisors. After data entry, random checks of $10 \%$ of the questionnaires were done. When households found having two or more eligible children, one of them was selected randomly via the lottery method.

The child dietary diversity, meal frequency, and minimum acceptable diet were assessed using the 24hours dietary recall method. The dietary diversity of children was calculated by a simple count of the number of food groups eaten 24-hours before the survey, regardless of the portion size using the WHO seven food group criteria [7]. The children's age was 


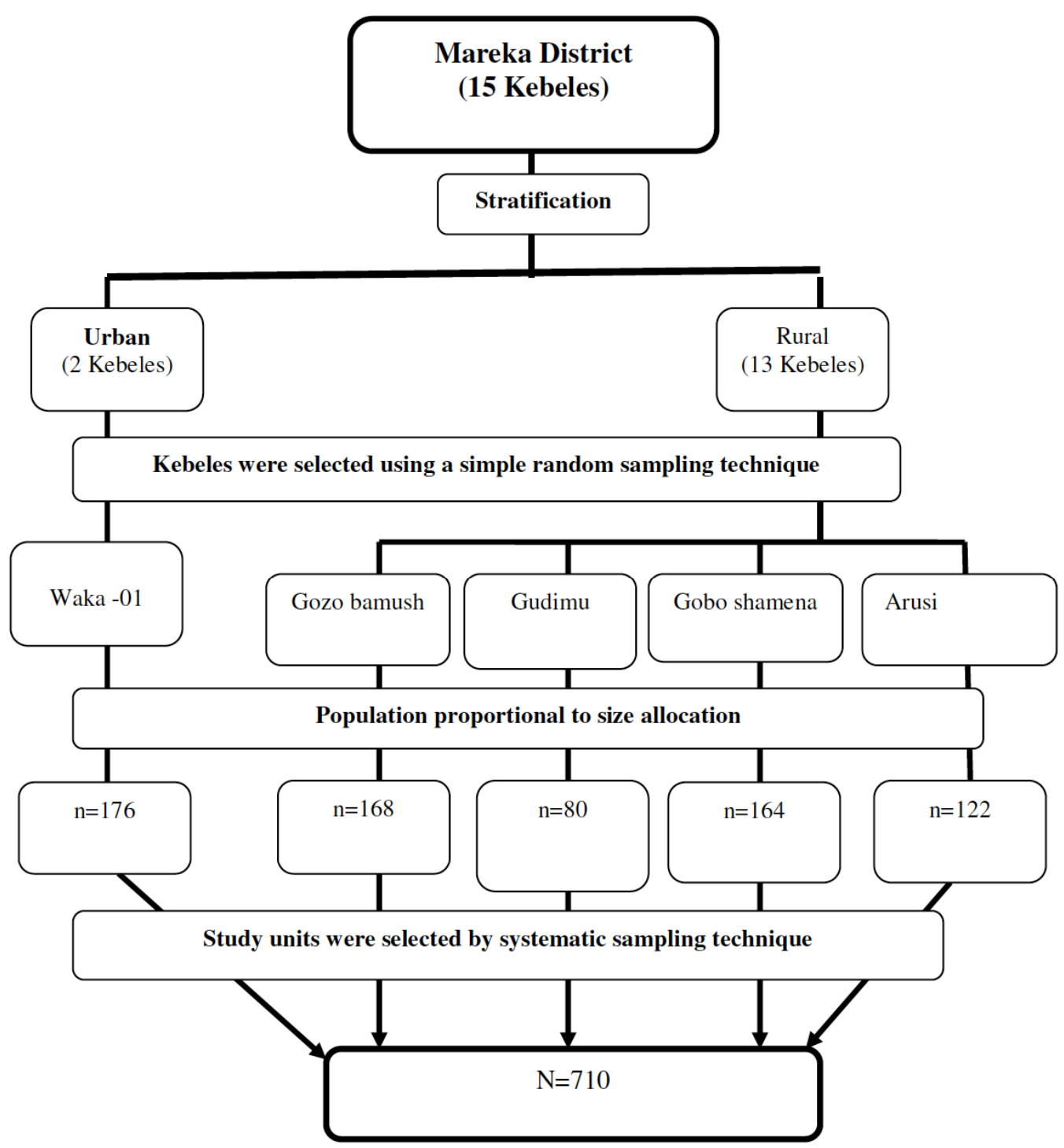

Figure 1: Schematic representations of the sampling procedure and sampling technique for selecting study participants to assess the level of MAD and predictors among children aged 6-23 months Mareka district, South Ethiopia, 2016.

assessed by local health extension roaster, vaccination status card, BCG scar, and mother recalled.

\section{Data Processing and Analysis}

After cleaning and editing, the data was entered into Epi-data version 3.1 and exported to the statistical package for social sciences (SPSS) software version 22 for further analysis. The result was presented using descriptive statistics such as frequency, percentage, bar graphs, and mean $( \pm S D)$.

The bivariable and multivariable logistic regression analyses were used to identify the potential predictors of the outcome variable. Independent variables that remain statistically significant in the bivariable analysis at $\mathrm{P}<0.25$ were entered into a multivariable logistic regression model. The wealth index was assessed using household assets via principal component analysis. The multicollinearity diagnosis was ruled-out with all standard errors being less than 2 . The overall percentage of the model accurately classified was $73.4 \%$, with Hosmer and Lemeshow's goodness-of-fit test $p$-value of 0.443 , indicating the model fits well [23]. Finally, the statistical association was declared at a $95 \%$ confidence interval with an adjusted odds ratio at the multivariable logistic regression model.

\section{Definition of Terms}

\section{Minimum Acceptable Diet (MAD)}

The percentage of breastfed children 6-23 months of age who had at least the minimum dietary diversity and the minimum meal frequency during the previous day, and non-breastfed children 6-23 months of age 
who received at least two milk feedings and had at least the minimum dietary diversity not including milk feeds and the minimum meal frequency during the previous day $[7,20]$.

\section{Minimum Dietary Diversity (MDD)}

Means when a child consumes at least four types of food groups from seven WHO recommended food groups, taken 24-hours before the survey, regardless of the portion size and meal frequency $[7,20]$.

\section{Minimum Meal Frequency (MMF)}

Calculated by grouping child age into two (6-8 months and 9-23 months). The acceptable MMF of children aged $6-8$ months is considered as two or more times per 24 hours, while for children aged 9-23 months, it is three or more times per 24-hours [7, 20].

\section{GMP Service Utilization}

Child weighed to growth monitoring and promotion service at least 5 and 4 times for 6-11 and 12-23 months of age per year, respectively [21, 22].

\section{RESULTS}

\section{Socio-Demographic Characteristics}

This study included 662 mother-child pairs with a response rate of $93.2 \%$. The majority, $629(95 \%)$ of them, were Dawro ethnic group. Around half,

Table 2: Socio-Demographic Characteristics of Study Participants in Mareka District, South Ethiopia, 2016 (n=662)

\begin{tabular}{|c|c|c|c|}
\hline \multicolumn{2}{|c|}{ Variables } & \multirow{2}{*}{$\frac{\text { Frequency (n) }}{125}$} & \multirow{2}{*}{$\begin{array}{c}\text { Percentage (\%) } \\
18.9\end{array}$} \\
\hline \multirow{3}{*}{ Maternal age (years) } & $15-24$ & & \\
\hline & $25-34$ & 404 & 61.0 \\
\hline & $35-49$ & 133 & 20.1 \\
\hline \multirow{2}{*}{ Maternal ethnicity } & Dawro & 629 & 95.0 \\
\hline & Others* & 33 & 5.0 \\
\hline \multirow{2}{*}{ Maternal religion } & Protestant & 612 & 92.2 \\
\hline & Others** & 50 & 7.8 \\
\hline \multirow{2}{*}{ Marital status } & Married & 655 & 98.9 \\
\hline & Others ${ }^{* * *}$ & 7 & 1.1 \\
\hline \multirow{3}{*}{ Maternal education } & No formal education & 333 & 50.3 \\
\hline & Primary & 210 & 31.7 \\
\hline & Secondary and above & 119 & 18.0 \\
\hline \multirow{3}{*}{ Paternal education } & No formal education & 295 & 44.6 \\
\hline & Primary & 240 & 36.3 \\
\hline & Secondary and above & 127 & 19.1 \\
\hline \multirow{3}{*}{ Household wealth index } & Low & 190 & 28.7 \\
\hline & Medium & 237 & 35.8 \\
\hline & High & 235 & 35.5 \\
\hline \multirow{3}{*}{ Household family size } & Mean \pm SD & \multicolumn{2}{|c|}{$(5.04 \pm 1.33)$} \\
\hline & $\leq 5$ & 443 & 66.9 \\
\hline & $>5$ & 219 & 33.1 \\
\hline \multirow{4}{*}{$\begin{array}{l}\text { Index child age in completed } \\
\text { months }\end{array}$} & Mean \pm SD & \multicolumn{2}{|c|}{$(14.35 \pm 5.24)$} \\
\hline & $6-8$ & 114 & 17.2 \\
\hline & $9-11$ & 128 & 19.3 \\
\hline & $12-23$ & 420 & 63.4 \\
\hline \multirow{2}{*}{ Child sex } & Female & 340 & 51.4 \\
\hline & Male & 322 & 48.6 \\
\hline
\end{tabular}

*Wolaita, Amhara and Kefa;** Orthodox, Catholic; ${ }^{* \star *}$ Divorced, widowed; ${ }^{* \star \star *}$ Merchant, a government employee. 
$333(50.3 \%)$ of mothers of index children were not educated. Regarding maternal occupation, 632 (95.5\%) were housewives. The mean $( \pm S D)$ age of children was $14.35( \pm 5.24)$ months (Table 2).

\section{Maternal and Child Healthcare-Related Characteristics}

Two-hundred ninety-two (44.1\%) of mothers did not attend antenatal care follow-up for the index child. Institutional delivery was $190(28.7 \%)$. About one-third of $(31.1 \%)$ mothers had a workload, and $28.7 \%$ of them had the birth order of the first child. The majority, $530(80.1 \%)$ of children, did not utilize GMP services (Table 3).

\section{Infant and Young Child Feeding (IYCF) Practices}

The study revealed that about $35.5 \%(95 \% \mathrm{Cl}: 32-$ 39 ) of children aged 6-23 months met the recommended level of MAD. The study also revealed that $577(87.2 \%)$ and $258(39 \%)$ of children had met the recommended MMF and MDD, respectively. But the level of MAD varies with age; it is lower among children aged 6-8 months (14.9\%) than children aged 12-23 months $(39.0 \%)$. The extent of consuming diverse food groups and meal frequency, 24-hours before the survey, also showed variation with child age. As the age of children increases, the uptake of MAD increases, but the meal frequency is reverse with the age of the child feeding practices (Figure 2).

Grains, roots, tubers (92\%), legumes, and nuts $(86 \%)$ were the most common food items consumed by the children 24-hours before the survey. But only $25 \%$ and $8 \%$ of children consumed vitamin-A rich fruit and vegetables, and flesh foods, respectively (Figure 3 ).

\section{Factors Associated with MAD}

Predictor variables that were statistically significant at $p$-value $<0.25$ at bi-variable analysis and were incorporated at the final multivariable logistic regression model were maternal education, paternal education, wealth index, media exposure, age of the index child, ANC follow-up, institutional delivery, postnatal care utilization, birth order, and GMP service utilization. But the variables that were declared as statistically significant predictors at the final model at $p$ value $<0.05$ were maternal education, child age, media

Table 3: Maternal and Child Healthcare-Related Characteristics on the MAD in Mareka District, South Ethiopia, 2016 $(n=662)$

\begin{tabular}{|c|c|c|c|}
\hline Variables & Category & Frequency (n) & Percentage (\%) \\
\hline \multirow{3}{*}{ Antenatal care } & No & 292 & 44.1 \\
\hline & $1-3$ & 139 & 21.0 \\
\hline & $\geq 4$ & 231 & 34.9 \\
\hline \multirow{2}{*}{ Place of delivery } & Health institution & 190 & 28.7 \\
\hline & Home & 472 & 71.3 \\
\hline Postnatal care & Yes & 310 & 46.8 \\
\hline Media exposure & Yes & 211 & 31.9 \\
\hline \multirow{4}{*}{ Birth order } & Mean \pm SD & \multicolumn{2}{|c|}{$(2.06 \pm 0.97)$} \\
\hline & First child & 190 & 28.7 \\
\hline & $2-3$ & 400 & 60.4 \\
\hline & $>3$ & 72 & 10.9 \\
\hline \multirow{3}{*}{ Under-five children } & One & 383 & 57.9 \\
\hline & Two & 235 & 35.5 \\
\hline & Three and above & 44 & 6.6 \\
\hline \multirow{2}{*}{ GMP service utilization } & No & 530 & 80.1 \\
\hline & Yes & 132 & 19.9 \\
\hline \multirow{3}{*}{ Time to initiate complementary feeding } & Before six months & 297 & 44.7 \\
\hline & Exactly at six months & 283 & 42.7 \\
\hline & After six months & 82 & 12.6 \\
\hline
\end{tabular}




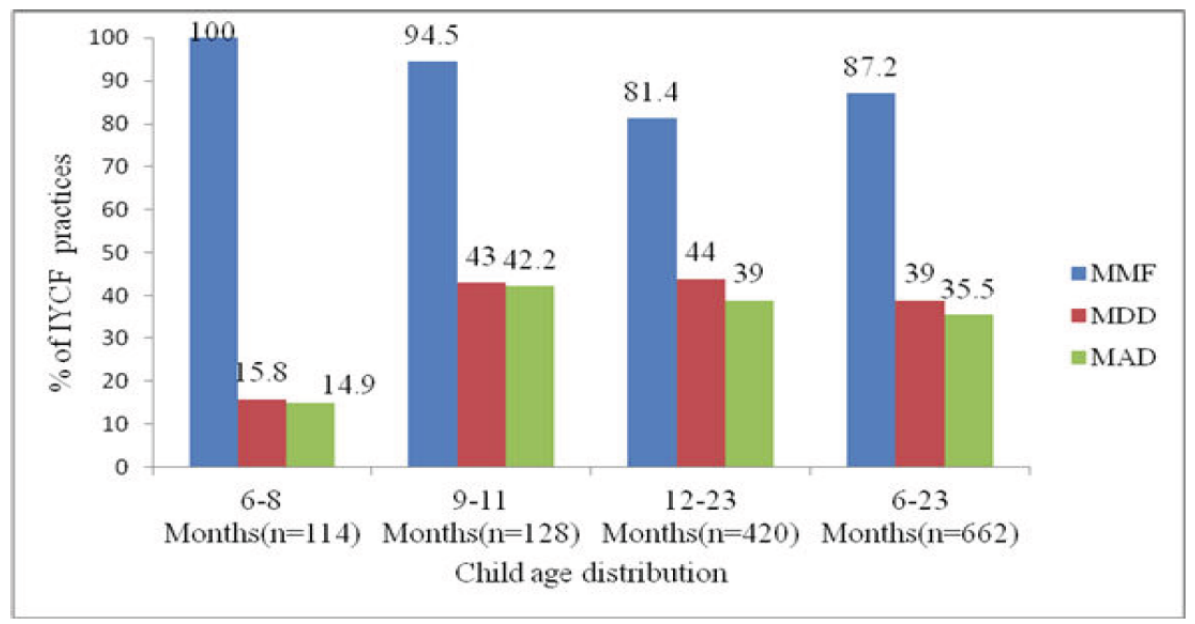

Figure 2: IYCF practices disaggregated by age in Mareka District, South Ethiopia, 2016 ( $n=662)$.

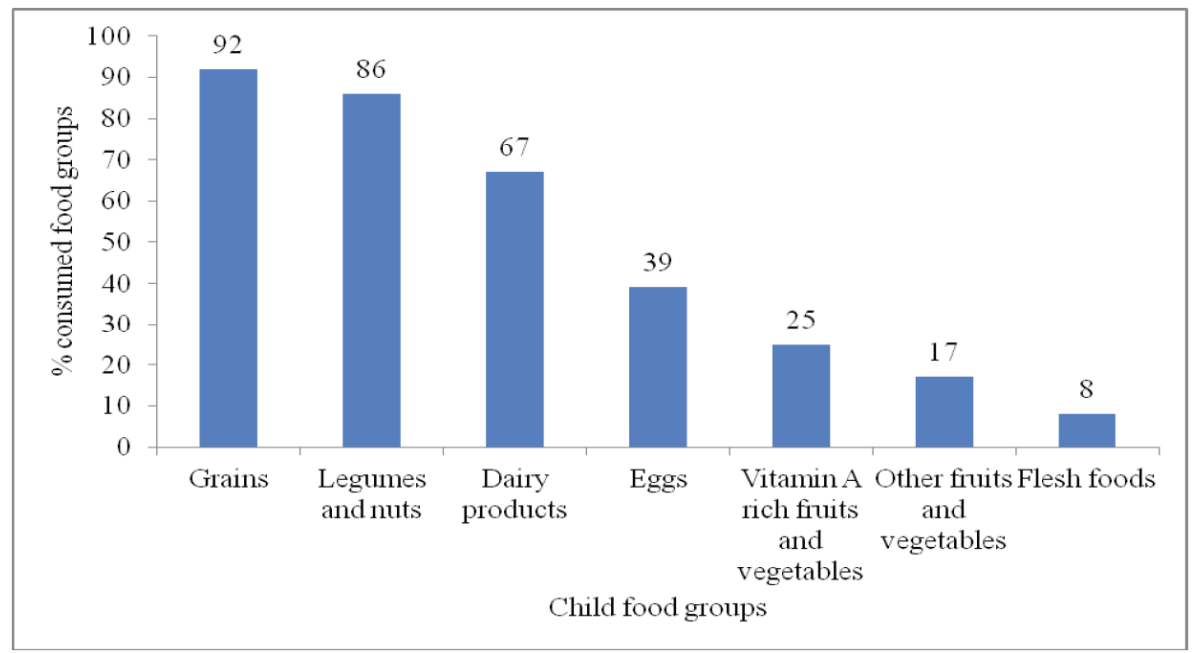

Figure 3: Percentage of each food group consumption by children aged 6-23 months 24-hours before the survey in Mareka District, south Ethiopia, $2016(n=662)$

exposure, institutional delivery, and GMP service utilization (Table 4).

\section{DISCUSSION}

To reduce malnutrition in a developing country like Ethiopia, adequate and safe infant, and young child feeding practice is crucial $[7,20]$. Optimal infant and young child feeding practices are defined within narrow age ranges, and these key feeding practices, within a continuum of child feeding, are used as an indicator of nutritional care practices [23]. Optimal complementary feeding is most effective in improving child growth and in reducing stunting among children 6-23 months of age [24].

This study revealed that around $35.5 \%$ (95\% Cl: $32-$ 39) of children met the MAD. This finding is higher than studies conducted in Dembech district, Amhara region
8.6\% [25], Golina district, Afar region 19.4 [26], and Babile, Enderta, and Hintalo Wajirat districts of Ethiopia [27]. It is also higher than the national findings [16, 28]. It might be due to sampling size, study area, and period. This finding is also higher than the study conducted in Tanzania 9\%, Pakistan $7.9 \%$, India 9.2\%, and Cambodia $28.3 \%$, in which only children met the MAD [18, 29-31] while less than studies conducted in Asian countries such Indonesia $44.9 \%$ [32], Sri Lanka $67.9 \%$ [30], Bangladesh $39.59 \%$ [33] and Mongolodia $43.8 \%$ [34], whereas it is nearly consistent with Nepal $31.8 \%[30]$.

In this study, maternal education, age of the index child, media exposure, place of delivery, and GMP utilization showed a statistically significant association with child MAD. Children from mothers who attended secondary and above level of education were more than two times to meet the MAD than children from 
Table 4: MAD Predictors among Children Aged 6 - 23 Months in Mareka District, South Ethiopia, 2016

\begin{tabular}{|c|c|c|c|c|c|}
\hline \multirow{2}{*}{ Variables } & \multirow{2}{*}{ Category } & \multicolumn{2}{|c|}{ MAD } & \multirow{2}{*}{ COR $(95 \% \mathrm{Cl})$} & \multirow{2}{*}{ AOR $(95 \% \mathrm{Cl})$} \\
\hline & & Met & Not met & & \\
\hline \multirow{3}{*}{ Maternal education } & Not educated & 82 & 251 & 1 & 1 \\
\hline & Primary & 93 & 117 & $2.43(1.68-3.52)$ & $1.90(1.15-3.16)$ * \\
\hline & Secondary and above & 60 & 59 & $3.11(2.01-4.82)$ & $2.06(1.12-3.77)$ * \\
\hline \multirow{3}{*}{ Paternal education } & Not educated & 80 & 215 & 1 & 1 \\
\hline & Primary & 99 & 141 & $1.89(1.31-2.71)$ & $0.86(0.51-1.43)$ \\
\hline & Secondary and above & 56 & 71 & $2.12(1.37-3.27)$ & $1.17(0.63-2.17)$ \\
\hline \multirow{3}{*}{ Wealth index } & Low & 82 & 147 & 1 & 1 \\
\hline & Medium & 61 & 144 & $0.76(0.51-1.14)$ & $0.90(0.56-1.46)$ \\
\hline & High & 92 & 136 & $1.21(0.83-1.77)$ & $0.82(0.53-1.29)$ \\
\hline \multirow{2}{*}{ Media exposure } & Satisfactory & 98 & 113 & $1.99(1.42-2.78)$ & $2.16(1.42-3.29)$ ** \\
\hline & Unsatisfactory & 137 & 314 & 1 & 1 \\
\hline \multirow{2}{*}{ ANC utilization } & Yes & 160 & 210 & $2.20(1.58-3.08)$ & $1.48(0.99-2.22)$ \\
\hline & No & 75 & 217 & 1 & 1 \\
\hline \multirow{2}{*}{ Delivery place } & Health facility & 115 & 75 & $4.50(3.15-6.23)$ & $2.52(1.54-4.13)$ ** \\
\hline & Home & 120 & 352 & 1 & 1 \\
\hline \multirow{2}{*}{ PNC utilization } & Yes & 150 & 160 & $2.93(2.11-4.07)$ & $1.24(0.77-1.99)$ \\
\hline & No & 85 & 260 & 1 & 1 \\
\hline \multirow{3}{*}{$\begin{array}{l}\text { Age of the index } \\
\text { child }\end{array}$} & 6 - 8 months & 17 & 97 & 1 & 1 \\
\hline & 9-11 months & 54 & 74 & $4.16(2.23-7.77)$ & $2.73(1.41-5.49)$ * \\
\hline & $12-23$ months & 164 & 256 & $3.49(2.11-6.34)$ & $2.55(1.39-4.69)$ * \\
\hline \multirow{3}{*}{ Birth order } & First child & 60 & 130 & 1 & 1 \\
\hline & $2-3$ & 152 & 248 & $1.33(0.92-1.92)$ & $1.83(0.76-1.83)$ \\
\hline & $>3$ & 23 & 49 & $1.02(0.57-1.82)$ & $0.55(0.27-1.23)$ \\
\hline \multirow{2}{*}{ GMP utilization } & No & 144 & 386 & 1 & 1 \\
\hline & Yes & 91 & 41 & $5.95(3.93-9.01)$ & $4.09(2.51-6.65)$ ** \\
\hline
\end{tabular}

${ }^{*} \mathrm{P}$-Value $<0.005$, and ${ }^{* *} \mathrm{P}$-Value $<0.0001$

non-educated mothers. This finding is in line with studies done in Ethiopia [25, 35, 36], Tanzania [31], Kenya, Uganda, and Nigeria [30, 37], and Asian countries [30]. This might be explained by; as the maternal education level becomes higher, her knowledge, attitude, and practice towards child feeding practice might be improved [26].

The age of the child was positively associated with MAD among children aged 6-23 months. Children in the age range of 9-11 and 12-23 months were more than two times more likely to meet the MAD than children aged 6-11 months. This finding is consistent with the evidence from Asia, Indonesia, Pakistan, Ghana, and Uganda [17, 32, 34, 38-40]. This might be due to the late introduction of complementary feeding, and even when they start complementary feeding on time; they included either only milk or cereal products. Another possibility could be mothers may perceive that the intestine of young children may not digest certain foods like banana, egg, pumpkin, carrot, green vegetables, and meat; as a result, they might not add such foods while they prepare complementary foods [20]. This could be further justified by mothers predisposing factors such as traditional beliefs and practices, during introducing optimal complementary food to infants in the rural community, infants may develop diarrhea due to poor hygienic condition, but mothers could associate this problem with taking different food items and eventually they might not permit the child to take such foods. It can be attributed to the feeding interest of the child too. This was supported by studies carried out in Indonesia, Nepal, Sri Lanka, and Ethiopia [18, 25, 28, 30, 40]. 
Children from mothers who were exposed to media (watched television, listened to the radio, and read newspapers or magazines) every day or at least once a week were more than two times more likely to meet MAD than those children from mothers who didn't. This study is similar to other studies conducted in Ethiopia and Asian countries [21, 25, 28, 35-37, 41]. The reason behind this could be that currently, most of the time, child feeding practices are promoted using different Media, which has the power to change the attitude and practices of individuals.

Other most important variables found to be associated with child MAD were institutional delivery. Children who were delivered at health institutions were also more than two and half times more likely to meet the MAD. Maternal counseling on infant and young child feeding practices after delivery in the health facility increases maternal knowledge, attitude, and practice on MAD. This finding is supported by studies in the northern part of Ethiopia [25].

Those children who utilized GMP service were more than three and half times more likely to meet MAD than children who didn't get GMP service. The GMP service utilization is conducted in every health facility using the WHO GMP chart monthly $[42,43]$. This might be as the HEWs monitor the weight of children using the standard GMP charts, and they will provide nutrition counseling to mothers or caregivers of children; as a result, there might be an improvement in child feeding practices [21]. This flinging is also supported by studies conducted in northern parts of Ethiopia, which indicated that there is more likely for meeting MAD on those children attending regular GMP services utilization at each health post level [21, 25, 43].

The possible limitations of this study could be the 24-hours dietary recall method might not show the usual intake and feeding pattern of the child. Recallbias might also be encountered. This indicator was designed to capture optimal complementary feeding patterns (based on WHO recommendations), but it was not designed to capture excessive intake of energy, sugar, or fat that would yield information about risks for overweight and obesity. It does not also provide quantitative information about children's food and nutrient intake. Some explanatory variables such as food security that might have a residual confounding on MAD were not assessed.

\section{CONCLUSION}

The study revealed that the level of MAD among children aged 6-23 months is low. Socio-demographic characteristics (such as maternal education, age of the index child, and media exposure), and maternal and child health-related characteristics (such as institutional delivery and GMP service utilization) were factors associated with MAD.

Therefore, strengthening emphasis on the importance of the education of girls (future mothers) is needed. It is also recommended that promoting and strengthening institutional delivery and GMP service utilization should be given emphasis.

\section{ABBREVIATIONS AND ACRONYMS}

$$
\begin{aligned}
& \text { AOR } \quad=\text { Adjusted Odds Ratio } \\
& \text { ANC }=\text { Antenatal Care } \\
& \text { BCG }=\text { Bacillus Calumet Guerin } \\
& \text { GMP }=\text { Growth Monitoring and Promotion } \\
& \text { HEP }=\text { Health Extension Program } \\
& \text { HEWs }=\text { Health Extension Workers } \\
& \text { HSTP }=\text { Health Sector Transformation Plan } \\
& \text { ITNs }=\text { Insecticide Treated bed Nets } \\
& \text { MAD }=\text { Minimum Acceptable Diet } \\
& \text { MDD }=\text { Minimum Dietary Diversity } \\
& \text { MMF }=\text { Minimum Meal Frequency } \\
& \text { NNP } \quad=\text { National Nutrition Program } \\
& \text { PNC = Postnatal Care } \\
& \text { SD } \quad=\text { Standard Deviation } \\
& \text { SPSS = Statistical Package for Social Sciences } \\
& \text { SURE = Sustainable Undernutrition Reduction in }
\end{aligned}
$$

UNICEF $=$ United Nations International Child Emergency Fund

$\mathrm{WHO}=$ World Health Organization

\section{ETHICAL CONSIDERATIONS}

An ethical clearance was obtained from Hawassa University Institutional review board ethical committee. A cooperation letter was taken to each Kebele after 
permission. Informed written consent was obtained from the participants. The confidentiality of participants was secured.

\section{CONSENT FOR PUBLICATION}

Not applicable.

\section{CONFLICT OF INTERESTS}

The authors declare that they have no conflict of interests.

\section{AUTHORS CONTRIBUTION}

FWF conceived and designed the study, performed analysis, interpreted the data. GFM is involved in the analysis, interpretation of the data. FWF and GFM prepare the manuscript. Both authors critically reviewed and approved the final manuscript.

\section{FUNDING}

This was a self-funded (from pocket) research. There were no external organizations that funded this research.

\section{AVAILABILITY OF DATA AND MATERIALS}

The data sets analyzed during the current study are available from the corresponding author upon reasonable request.

\section{ACKNOWLEDGEMENT}

Special thanks to Hawassa University for ethical approval of the study.

\section{REFERENCES}

[1] Micha R, Mannar V, Afshin A, Allemandi L, Baker P, Battersby J, et al 2020 Global nutrition report: action on equity to end malnutrition 2020.

[2] World Health Organization. Stunting policy brief. Available online: http://www.who.int/nutrition/topics/globaltargets_ stunting_policybrief.pdf 2018.

[3] Black RE, Victora CG, Walker SP, Bhutta ZA, Christian P, De Onis $\mathrm{M}$, et al. Maternal and child undernutrition and overweight in low-income and middle-income countries. The lancet 2013; 382(9890): 427-51. https://doi.org/10.1016/S0140-6736(13)60937-X

[4] United Nations Children's Fund (UNICEF) Division of Communication. Tracking progress on child and maternal nutrition: a survival and development priority: Unicef; 2009.

[5] Abera K. Infant and young child feeding practices among mothers living in Harar, Ethiopia. Harar Bulletin of Health Sciences 2012; 4: 66-78.

[6] World Health Organization. Guiding principles for feeding non-breastfed children 6-24 months of age2005.
[7]

World Health Organization. Indicators for assessing infant and young child feeding practices: part 1: definitions: conclusions of a consensus meeting held 6-8 November 2007 in Washington DC, USA2008.

Victora CG, Adair L, Fall C, Hallal PC, Martorell R, Richter L, et al. Maternal and child undernutrition: consequences for adult health and human capital. The Lancet 2008; 371(9609): 340-57. https://doi.org/10.1016/S0140-6736(07)61692-4

[9] Federal Democratic Republic of Ethiopa. National Nutrition Programe (2016-2020) 2016.

[10] Ethiopian Federal Ministry of Health. Health Sector Transformation Plan 2015/16-2019/20. Federal Democratic Republic of Ethiopia, Ministry of Health Addis Ababa, Ethiopia. 2015.

[11] Ethiopian Public Health Institute. Reducing Stunting in Ethiopia: "From Promise to Impact"; An Evidence-Informed Policy Brief (2019) 2019.

[12] Wang H, Tesfaye R, NV Ramana G, Chekagn CT. Ethiopia health extension program: an institutionalized community approach for universal health coverage: The World Bank; 2016.

https://doi.org/10.1596/978-1-4648-0815-9

[13] Federal Democratic Republic of Ethiopia Ministry of Health and Ministry of Agriculture and Natural Resources. Complementary feeding for children 6 - 24 months of age; recipes based on locally available food items: SURE program 2017.

[14] Federal Democratic Republic of Ethiopia. Seqota Declaration implementation plan 2016-2030 2016.

[15] Ethiopian Public Health Institute (EPHI) [Ethiopia] and ICF 2019. Ethiopia Mini Demographic and Health Survey 2019: Key Indicators. Rockville, Maryland, USA: EPHI and ICF.

[16] Central Statistical Agency (CSA) [Ethiopia] and ICF 2016. Ethiopia Demographic and Health Survey 2016: Key Indicators Report. Addis Ababa, Ethiopia, and Rockville, Maryland, USA. CSA and ICF.

[17] Issaka $\mathrm{Al}$, Agho $\mathrm{KE}$, Burns $\mathrm{P}$, Page A, Dibley MJ. Determinants of inadequate complementary feeding practices among children aged 6-23 months in Ghana. Public Health Nutr 2015; 18(4): 669-78. https://doi.org/10.1017/S1368980014000834

[18] Reinbott A, Kuchenbecker J, Herrmann J, Jordan I, Muehlhoff $\mathrm{E}$, Kevanna $\mathrm{O}$, et al. A child feeding index is superior to WHO IYCF indicators in explaining length-for-age Z-scores of young children in rural Cambodia. Paediatr Int Child Health 2015; 35(2): 124-34. https://doi.org/10.1179/2046905514Y.0000000155

[19] Victor R, Baines SK, Agho KE, Dibley MJ. Factors associated with inappropriate complementary feeding practices among children aged 6-23 months in Tanzania. Matern Child Nutr 2014; 10(4): 545-61. https://doi.org/10.1111/j.1740-8709.2012.00435.x

[20] World Health Organization. Indicators for assessing infant and young child feeding practices: part 2: measurement 2010.

[21] Feleke FW, Adole AA, Bezabih AM. Utilization of growth monitoring and promotion services and associated factors among under two years of age children in Southern Ethiopia. PloS One 2017; 12(5): e0177502. https://doi.org/10.1371/journal.pone.0177502

[22] Faber M, Phungula MA, Kvalsvig JD, Benadé AS, Young $H$. Acceptability of community-based growth monitoring in a rural village in South Africa. Food and Nutrition Bulletin 2003; 24(4): 350-9.

https://doi.org/10.1177/156482650302400405

[23] CARE USA. Infant and young child feeding practices. Collecting and Using Data: A Step-by-Step Guide: Available online at: https://www.ennonline.net/iycfdataguide 2010. 
[24] United Nations International Child Emergency Fund (UNICEF). Infant and young child feeding: programming guide. New York 2011: 17-8.

[25] Mulat E, Alem G, Woyraw W, Temesgen H. Uptake of minimum acceptable diet among children aged 6-23 months in orthodox religion followers during fasting season in rural area, Dembecha, north West Ethiopia. BMC Nutr 2019; 5: 18.

https://doi.org/10.1186/s40795-019-0274-y

[26] Fentaw Mulaw G, Wassie Feleke F, Adane Masresha S. Maternal Characteristics Are Associated with Child Dietary Diversity Score, in Golina District, Northeast Ethiopia: A Community-Based Cross-Sectional Study. Journal of Nutrition and Metabolism 2020; 2020. https://doi.org/10.1155/2020/6702036

[27] Roba KT, O'Connor TP, Belachew T, O'Brien NM. Infant and young child feeding (IYCF) practices among mothers of children aged 6-23 months in two agro-ecological zones of rural Ethiopia. Int J Nutr Food Sci 2016; 5(3): 185-94. https://doi.org/10.11648/j.ijnfs.20160503.16

[28] Tassew AA, Tekle DY, Belachew AB, Adhena BM. Factors affecting feeding 6-23 months age children according to minimum acceptable diet in Ethiopia: A multilevel analysis of the Ethiopian Demographic Health Survey. PLoS One 2019; 14(2): e0203098.

https://doi.org/10.1371/journal.pone.0203098

[29] Nawaz R, Khalid A, Hanif M, Razaq A. Lepiota vellingana sp. nov.(Basidiomycota, Agaricales) a new species from Lahore, Pakistan. Mycological Progress 2013; 12(4): 727-32. https://doi.org/10.1007/s11557-012-0884-0

[30] Senarath U, Agho KE, Akram DE, Godakandage SS, Hazir T, Jayawickrama $\mathrm{H}$, et al. Comparisons of complementary feeding indicators and associated factors in children aged 623 months across five South Asian countries. Matern Child Nutr 2012; 8 Suppl 1(Suppl 1): 89-106. https://doi.org/10.1111/j.1740-8709.2011.00370.x

[31] Ogbo FA, Ogeleka $P$, Awosemo AO. Trends and determinants of complementary feeding practices in Tanzania, 2004-2016. Trop Med Health 2018; 46: 40. https://doi.org/10.1186/s41182-018-0121-x

[32] $\mathrm{Ng} \mathrm{CS}$, Dibley MJ, Agho KE. Complementary feeding indicators and determinants of poor feeding practices in Indonesia: a secondary analysis of 2007 Demographic and Health Survey data. Public Health Nutr 2012; 15(5): 827-39. https://doi.org/10.1017/S1368980011002485

[33] Kabir I, Khanam M, Agho KE, Mihrshahi S, Dibley MJ, Roy SK. Determinants of inappropriate complementary feeding practices in infant and young children in Bangladesh: secondary data analysis of Demographic Health Survey 2007. Matern Child Nutr 2012; 8 Suppl 1(Suppl 1): 11-27. https://doi.org/10.1111/j.1740-8709.2011.00379.x
[34] Janmohamed A, Luvsanjamba M, Norov B, Batsaikhan E, Jamiyan B, Blankenship JL. Complementary feeding practices and associated factors among Mongolian children 6-23 months of age. Matern Child Nutr 2020: e12838. https://doi.org/10.1111/mcn.12838

[35] Beyene M, Worku AG, Wassie MM. Dietary diversity, meal frequency and associated factors among infant and young children in Northwest Ethiopia: a cross-sectional study. BMC Public Health 2015; 15(1): 1007. https://doi.org/10.1186/s12889-015-2333-x

[36] Tsedal DM, Yitayal M, Abebe Z, Tsegaye AT. Effect of intimate partner violence of women on minimum acceptable diet of children aged 6-23 months in Ethiopia: evidence from 2016 Ethiopian demographic and health survey. BMC Nutr 2020; 6 : 28.

https://doi.org/10.1186/s40795-020-00354-7

[37] Senarath U, Godakandage SS, Jayawickrama $H$, Siriwardena I, Dibley MJ. Determinants of inappropriate complementary feeding practices in young children in Sri Lanka: secondary data analysis of Demographic and Health Survey 2006-2007. Matern Child Nutr 2012; 8 Suppl 1(Suppl 1): $60-77$. https://doi.org/10.1111/j.1740-8709.2011.00375.x

[38] Mokori A, Schonfeldt $H$, Hendriks SL. Child factors associated with complementary feeding practices in Uganda. South African Journal of Clinical Nutrition 2017; 30(1): 7-14. https://doi.org/10.1080/16070658.2016.1225887

[39] $\mathrm{Na}$ M, Aguayo VM, Arimond M, Dahal P, Lamichhane B, Pokharel $\mathrm{R}$, et al. Trends and predictors of appropriate complementary feeding practices in Nepal: An analysis of national household survey data collected between 2001 and 2014. Matern Child Nutr 2018; 14 Suppl 4(Suppl 4): e12564. https://doi.org/10.1111/mcn.12564

[40] Khan AM, Kayina P, Agrawal P, Gupta A, Kannan AT. A study on infant and young child feeding practices among mothers attending an urban health center in East Delhi. Indian journal of public health 2012; 56(4): 301. https://doi.org/10.4103/0019-557X.106420

[41] Khanal V, Sauer K, Zhao Y. Determinants of complementary feeding practices among Nepalese children aged 6-23 months: findings from Demographic and Health Survey 2011. BMC Pediatr 2013; 13: 131 https://doi.org/10.1186/1471-2431-13-131

[42] Gautam KP, Adhikari M, Khatri RB, Devkota MD. Determinants of infant and young child feeding practices in Rupandehi, Nepal. BMC Res Notes 2016; 9: 135. https://doi.org/10.1186/s13104-016-1956-z

[43] Bilal SM, Moser A, Blanco R, Spigt M, Dinant GJ. Practices and challenges of growth monitoring and promotion in Ethiopia: a qualitative study. Journal of Health, Population, and Nutrition 2014; 32(3): 441.

(c) 2020 Feleke and Mulaw; Licensee Lifescience Global.

This is an open access article licensed under the terms of the Creative Commons Attribution Non-Commercial License (http://creativecommons.org/licenses/by-nc/3.0/) which permits unrestricted, non-commercial use, distribution and reproduction in any medium, provided the work is properly cited. 